\title{
A Gendered Analysis of Fisherfolk's Livelihood Adaptation and Coping Responses in the Face of a Seasonal Fishing Ban in Tamil Nadu \& Puducherry, India
}

\author{
JULIA M. NOVAK COLWELL ${ }^{\mathrm{a}, \mathrm{b}}$, MARK AXELROD ${ }^{\mathrm{b}}$, SHYAM S. SALIM $^{\mathrm{c}}$ and S. VELVIZHI $^{\mathrm{d},{ }^{*}}$

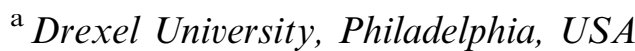 \\ ${ }^{\mathrm{b}}$ Michigan State University, East Lansing, USA \\ ${ }^{\mathrm{c}}$ Central Marine Fisheries Research Institute, Ernakulam, India \\ ${ }^{\mathrm{d}}$ M.S. Swaminathan Research Foundation, Nagappattinam, India
}

\begin{abstract}
Summary. - This study investigates how people respond to economic stresses incurred as a result of natural resource regulations. Previous research has demonstrated that in some cases, men and women adapt differently to livelihood stresses. We argue that looking only at an individual's sex is insufficient for understanding why they adapt the way they do. Instead, using the framework of intersectionality, we examine individuals' adaptation strategies and coping responses influenced not only by their sex but also their power and class. Using the case of a closed fishing season in Tamil Nadu and Puducherry, India we employ interviews, seasonal activities calendars, and surveys to identify key variables that influence an individual's likelihood of employing reactive strategies that may threaten their longer term livelihood sustainability. We show that if we categorize individuals only by sex, then women are more likely to resort to reactive coping than men. However, this sex divide in reactive coping is driven by particular subsets of people who also lack power and/or capital. Furthermore, we find that power and class lead to different outcomes for men and women, with networked power most helpful to women above a certain financial threshold. This study highlights the necessity of examining gender and livelihood adaptations beyond the male versus female dichotomy: considering intersecting and locally relevant measures of power, class, and sex are pivotal in understanding why people adapt and cope the way they do. This understanding of adaptation options may also have implications for resource management decisions that do not force individuals to choose between long-term livelihood resilience and response to immediate stresses.

(c) 2017 Elsevier Ltd. All rights reserved.
\end{abstract}

Key words - gender, fisheries, adaptation, coping, intersectionality, India

\section{INTRODUCTION}

It is well documented in the sustainable livelihoods literature that men and women often respond differently to stresses and shocks affecting their livelihoods. Certain adaptation and coping strategies may jeopardize one's longer term ability to respond to stresses or bounce back from other shocks. An individual's choices, therefore, may have a legacy effect on their long-term livelihood resilience (i.e., their ability to bounce back from future shocks).

Livelihoods and resilience research has addressed the socalled "gender gap" in adaptations: i.e., men and women tend to adapt differently to stresses (Hussein \& Nelson, 1998). This differential response to stress has been shown in the case of the fisheries sector in Sierra Leone where men and women respond differently to stresses due to differential access to assets and other resources that result from gendered institutional arrangements (Thorpe, Pouw, Baio, Sandi, Ndomahina, \& Lebbie, 2014). In times of severe stress, some scholars find that women are more likely to cut back on the amount of food they eat to conserve funds and/or ensure their family members have sufficient nutrition (Kabeer, 2015; Kiewisch, 2015). This is an example of a reactive coping strategy that may have long-term consequences for their own human capital (health). These reactive responses are otherwise known as coping (Niehof, 2004) or ex post risk management (de Haan \& Zoomers, 2005), in contrast with proactive adaptation strategies (or $e x$ ante risk management strategies).

There has been a great deal of feminist research on gender and the environment which has focused on women's relation- ship with nature. Some of this research has suggested that women are naturally closer to nature and therefore more impacted by environmental degradation and policies (Shiva, 1988). Other feminist scholars argue that-while women are in fact more impacted by declining resource health - the adaptation gap is driven primarily by the roles women take on in everyday life (like subsistence food production) (Agarwal, 2001; Jackson, 1993). Still other scholars assert that the disproportional impact on women is caused by the ways in which they have been involved, historically, in the production sector, such that women frequently have depressed access to productive assets, tenure, and disproportionately occupy jobs in the informal economy in greater numbers than men. These historical roles women have played in relation to the production sector condition their access to, and power over, resources (Carney, 1994; Rocheleau, Thomas-Slayter, \& Wangari, 1996). Conversely, other scholars caution against simplifying relationships between environmental degradation and impacts

\footnotetext{
* This research was funded by a Fulbright-Nehru Student Research Scholarship (Grant number 2014/ST/20). Previous versions of this work were presented at the 2016 IIFET conference in Aberdeen, Scotland. The authors thank John Kerr, Linda Racioppi and Brian Roth (Michigan State University) who provided helpful feedback in the preparation of this research article. The authors thank Dr. A. Gopalakrishnan (Central Marine Fisheries Research Institute, Kochi, Kerala) and M.S. Swaminathan Research Foundation, Nagappattinam, Tamil Nadu for their help in coordinating research activities and administrative support. Final revision accepted: April 30, 2017.
} 
to women indicating that by assuming women are victims, important connections between environmental outcomes and injustices are overlooked (Detraz, 2017).

We argue that none of these approaches in isolation are sufficient for understanding how and why women and men make particular livelihood choices in some contexts. Outside of natural resources, there is a rich literature on the intersectionality between sex, class, and power in conditioning experiences of gender (McCall, 2001; Weber, 2010). Intersectionality is "the interaction of multiple identities and experiences of exclusion and subordination" (Davis, 2008, p. 67).

However, resource management research is largely lacking in this area (Braun, 2015). Some scholars have shown the applicability of the intersectionality framework in understanding gendered experiences of poverty and associated responses to shocks (Kabeer, 2015) while others have shown how intersectionality and environmental justice frameworks can be combined to better understand gendered effects of development projects (Braun, 2015). This study aims to show how incorporating the intersectionality framework into an analysis of gendered adaptation and coping responses can lead to an increased understanding of individual-level outcomes. We operationalize gender as the intersection between sex, class, and power, and assess these factors' interactive impact on adaptation choices in the context of natural resource management.

Without considering these interactions, we risk oversimplifying relationships between livelihood adaptations and gender (if only considering gender as male vs. female) and maintaining superficial levels of understanding (Arora-Jonsson, 2011). Our results show that sex by itself does not fully explain adaptation options employed as part of one's livelihood strategy; power and class condition the impact of sex on one's adaptation choices.

Our findings also have potential policy implications. By understanding the factors that may intersect to make an individual more likely to employ a reactive response, decision makers can consider more nuanced programs that enable individuals to avoid jeopardizing long-term livelihood resilience when dealing with immediate stresses incurred from resource management regulations.

In this paper, we first outline why it is important to investigate natural resource management issues through a gendered lens. We then go on to show how the intersectionality framework can be a useful tool in understanding resource management issues, followed by a presentation of how this research uses the framework to investigate differential responses to stress. We then present the hypotheses and research methods followed by a discussion of the results, which suggest that sex alone does not explain an individual's adaptation or coping choices in the study communities; instead various configurations of sex, power, and class intersect to significantly impact responses. We conclude by demonstrating the implications of these findings.

\section{(a) Importance of examining adaptation and coping through a gendered lens}

Adaptation strategies are employed by people responding to stresses - including economic, ecological, and regulatory changes - in order to adjust and become better able to handle new conditions. Adaptation strategies are strategies used in response to stresses that are faced over the long term and could involve diversification of assets, activities, etc. (Ellis, 2000). An example of an adaptation strategy in the fisheries sector may be to invest in boats in order to be able to take advantage of periods of high fish abundance (Allison \& Ellis, 2001). Coping is a response to short-term surprises (i.e., shocks) and may include divestment of productive assets (Heltberg, Hossain, Reva, \& Turk, 2012).

In various contexts, a basic sex divide has been uncovered between men's and women's abilities and options when responding to livelihood stresses or shocks (Heltberg et al., 2012; Hussein \& Nelson, 1998). As noted earlier, in periods of prolonged stress leading to food insecurity, it is often women who are first to reduce their food consumption in order to cope with insufficient income (Kiewisch, 2015). This is an example of reactive coping, or an ex-post risk management strategy, that may jeopardize long-term adaptive capacity and livelihood resilience. Toulmin (1992) outlines the gender-differentiated responses to the seasonal stresses incurred in agricultural areas, showing that men and women diversify differently due to gender-specific constraints and opportunities. In the fisheries sector specifically, men and women may have different adaptation opportunities due to differential access to credit, capital, or cultural constraints. For example, Bennett (2005) argues that while women typically have more access to credit than men, they do not necessarily have power over how they use the credit thus increasing their vulnerability. Cultural factors may also narrow women's adaptation options by eliminating particular livelihood alternatives such as fish harvesting (Rubinoff, 1999).

Looking at gender as a key explanatory factor in predicting adaptation and coping strategies becomes essential in understanding outcomes. However, scholars have both advocated for and cautioned against examining issues through "gendered lenses". Some feminist scholarship (Cornwall, 2003) has suggested that research and policies that focus only on women, particularly token women chosen to represent the interests of their sex, can further marginalize other women and also large segments of the male population. Furthermore, examining issues through outdated lenses can push agendas that are ill-informed or incomplete (Runyan, Sisson, \& Spike, 2013). This practice in research can lead to the production of institutions that exacerbate existing inequitable power structures. For example, in some cases the advocacy of women's inclusion in local decision-making may reify the power of upper class/caste individuals over other marginalized groups if upper class women are selected to represent the whole sex (Cornwall, 2003). Conceptualizing gender as more than just women is therefore important, as is understanding gender as it is contextualized by place (Hawkins \& Ojeda, 2011). Utilizing gendered lenses by focusing on gender as multiple, intersecting forms of power relationships between different individuals can be an important tool in understanding both high-level processes and individual-level relationships (Detraz, 2017). This also includes incorporating men into the gender discourse, as well as acknowledging that not all women or all men have the same experience or opportunities. Ray (2007) argues that this more nuanced understanding of gender is essential in understanding which individuals are impacted by natural resource management policies, and how they are affected.

\section{(b) Intersectional analysis as a useful tool in studying natural} resource management issues

The intersectionality framework, as found in feminist literature can be a useful tool to apply in a natural resource management context, where differential individual-level responses to stresses or shocks are identified but not clearly understood. The intersectionality framework examines individuals' variable experiences with sex, power, class, and other forms of 
social difference that interact to shape their identity and experiences (Weber, 2010).

An example of intersectionality and its impact on adaptation can be seen through gendered restrictions on movement, which limit learning opportunities that may in turn limit an individual's adaptation choices (Barrig, 2006; Ram, 1991). To this end, an individual's ability to access education or plan for certain livelihoods or professions may be influenced not only by their sex, but their power within their family, their household responsibilities, and cultural constraints on acceptable livelihoods or professions. Their ability to attend school and make choices about their future may be influenced not only by their financial ability, but class expectations of gendered behavior by individuals within their class group, among a variety of other factors. For example, Agarwal (2001) asserts that lower caste ${ }^{1}$ women in India have less strict socially dictated rules on movement and speech than upper caste women. Caste, class, and power therefore intersect to condition the impact of sex differences on other outcomes.

Within the fisheries sector, some scholars have shown the utility of examining gender through intersecting identities of class, caste, and power in determining the livelihood options available to men and women (Hapke \& Ayyankeril, 2004) while others have shown how an intersectional analysis of power conditions unexpected outcomes of fisheries decentralization (Béné et al., 2009; Njaya, Donda, \& Béné, 2012). Outside of fisheries, other scholars have shown the utility of intersectional analysis in understanding resource access and use patterns (Lau \& Scales, 2016) and in investigating the diverse implications of climate change for different individuals and groups (Kaijser \& Kronsell, 2013). Within these contexts, power becomes a primary variable of interest.

\section{(c) Using the intersectionality framework to investigate differential responses to stress}

This study focuses on how we can operationalize intersectionality in the context of natural resource management to understand differential responses of individuals to livelihood stresses. We do this by pairing data derived from qualitative interviews and participant observation with quantitative, individual-level survey data and locally contextualized measures of power and class. We adopt the definition outlined by Allen (1998) of power, which suggests that power is the ability of an actor or set of actors to act. This definition is purposefully broad because she goes on to specify modalities of this power. To this end, she argues that in each situation, different forms of power may play important roles.

The first manifestation of power is power over, also known as domination or the ability to have power over someone else's choices and actions. The second manifestation of power is power with, or the power that is derived from a collective working together (i.e., group agency). The third manifestation is the power to, exhibited by the ability to get something done or to achieve an end.

Power derived from networks can heavily influence an individual's adaptation options. For example, individuals without social networks beyond their communities [or with weak networks inside their communities] may be limited in alternative employment opportunities (Putnam, 1993). In India, selfhelp groups (SHGs) are a type of collective that has been a popular tool for rural development. SHG membership is usually comprised largely of women. Although SHGs have had mixed success in the Indian context, their underlying premise of increasing savings and access to credit for members, as well as social empowerment, has maintained their popularity within development circles and with the government of India (Self-Help Groups: India, 2005). There is some evidence that women have used their collective power attained through SHGs to bypass local, male-dominated governance structures, to access state mechanisms for their community's benefit (Kruks-Wisner, 2011). This increased access to state and local decision-making bodies has the potential to influence an individual's adaptation options.

Other research has highlighted women's increased use of networks to overcome unequal natural resource access arrangements. For example, to secure access to water, women use informal social networks in the absence of formal rights (Ray, 2007). Along similar lines, other research has suggested that women are more likely to invest their time and energy into strengthening social networks at the expense of building productive capital, with the aim of securing access to resources especially during times of scarcity (Berry, 1989). Finally, in research highlighting women's unequal access to market information, Young (1993) suggests that women tend to rely more on social networks, in contrast with men who rely on more formal networks. The above scholarship highlights the importance of social networks, whether it be inter or intra community networks or group membership for women, especially in gaining the power necessary to expand livelihood adaptation options.

Class and power have been considered by some scholars to be tightly linked (Nightingale, 2011). An individual's social class can impact their ability to diversify to different income streams (Haque, Idrobo, Berkes, \& Giesbrecht, 2015). A lack of financial assets may prohibit an individual from buying other assets that would increase their ability to diversify. This inability to diversify may then constrain an individual's other adaptation options. However, overspecialization within a particular industry, like a fishery, can also limit one's adaptation options unless the individual simultaneously invests in a safety net (Allison \& Ellis, 2001). Financial capital is the most versatile form of capital (Kollmair \& St. Gamper, 2002), and a lack of financial capital can be the primary limiting factor for diversification and adaptation (Haque et al., 2015).

An individual's sex can also impact their ability to diversify, but is conditioned by social class (Niehof, 2004). For example, Niehof (2004) discusses a case in Indonesia where sex and class intersect to determine the livelihood diversification options open for men and women. In this case, work for lower class men is prevalent in their home villages. However, women of lower class households, who also are expected to contribute to household earning, must migrate out to cities where work as petty traders and vendors is viable. Therefore, being of lower class and being a woman intersect to influence the need and social acceptance of female migration and associated ability of these women to diversify their livelihoods.

Within the fish-processing sector in West Africa, Thorpe et al. (2014) show how class interacts with sex to influence adaptation options. In this case, a hierarchy within the female fish-processing sector influences an individual's access to fish, the quality of that fish and access to the post-harvest supply and distribution chain.

Finally, women may have less access to productive assets than men (Buvinić \& Gupta, 1997), thereby limiting class mobility. This decreased access may be the result of power imbalances, institutional arrangements, or place-based gender realities where women's domestic responsibilities limit their ability to accumulate assets and thus the adaptation options available to them (Thorpe et al., 2014). Decreased access to productive assets may lead to livelihood options that are less capital intensive. In many cases, these options may be less 
profitable (i.e., headloading versus mechanized fishing), but in others the lower investment costs may lead to higher relative profits. Hence, the type of productive assets owned by women and men may be quite different in certain cases. Additionally, men and women may have different levels of control over their own labor and the opportunity to be in control of someone else's labor (Kabeer, 2015).

\section{(d) Hypotheses}

Based on the above literature, we hypothesize that an individual's sex, conditioned by power and class, influences adaptation and coping. We refer to this difference as the "sex divide" in coping. We hypothesize that when power and class are taken into account, the relationship between sex and the likelihood of coping will be further specified. For example, women with power and/or from a higher social class may be less likely to resort to reactive coping that compromises their long-term livelihood resilience. Conversely, we hypothesize that women with no observable measure of power and from a lower class will more likely resort to reactive coping. Furthermore, males of low power and class may also pursue reactive strategies. However, we hypothesize that power and class may lead to different strategies for men vs. women.

H0. The sex divide is consistent at all levels of power or class.

H1. There is a sex divide in the likelihood of employing a reactive strategy, but this divide is contingent on various configurations of power and class.

H1a. The sex divide is insignificant at upper class and high power levels.

H2. Power and class have different impacts for men and women.

H2a. The impact of power on the likelihood of employing a reactive strategy changes with different configurations of sex and class.

H2b. The impact of class on the likelihood of employing a reactive strategy changes with different configurations of sex and power.

\section{METHODS}

\section{(a) The Indian fisheries Context: A case for analysis}

The fisheries sector in Tamil Nadu and neighboring Puducherry, India was chosen as the case for analysis as it is characterized by a deeply entrenched gender division of labor (Rubinoff, 1999) present in many fishing communities around the globe. The gender division of labor is not manifested simply by different jobs allocated to men versus women; it is manifested through differences in power relationships, access to resources and culturally constructed notions of an individual's capabilities (Jackson, 1993). Women are responsible for much of the pre and post-harvest activities, as are individuals of Scheduled Castes and Tribes (ICSF, 2005), who are often among the lowest class (in economic terms) as well. Within Tamil Nadu, women make up over $70 \%$ of the post-harvest workforce (CMFRI, 2010b), responsible for jobs such as headloading (selling fish house to house via baskets on their head), market vending, and fish processing, among others. Only men may work in the harvest sector, though there is also a significant male presence in more export-oriented post-harvest work, as well as transport, resupply, and maintenance activities that ensure boats and crew are prepared for their next trip.

In Tamil Nadu and Puducherry (and similarly throughout coastal India), a seasonal fishing ban was implemented in 2001 and applies to mechanized boats (boats with engines over $25 \mathrm{hp}$ and machines rather than fishermen hauling in the nets). It halts mechanized fishing for 45 days annually, from 15 April to 29 May. $^{2}$ It was negotiated between the government and fishing communities for two reasons. The first reason was that it was meant to serve as a conflict resolution mechanism in response to increasing conflict between smaller scale (artisanal), non-mechanized fishers and mechanized boats who often destroyed artisanal gear and landed larger quantities of fish. Second, it was meant to protect spawning populations of fish during peak reproductive times, thus allowing time for the regeneration of the fishery (Vivekanandan, Narayanakumar, Najmudeen, Jayasankar, \& Ramachandran, 2010).

The ban is jointly implemented by the state and district fisheries departments, local Boat Owners Associations (BOAs) and village-level governance bodies (panchayats). At the state and district level, the harbors are physically closed (chained) which prevents mechanized boats from leaving and tax-free diesel (provided by the district fisheries departments) ceases to be available during this time. Local Boat Owners Associations and village governance bodies monitor their members and impose penalties for non-compliance such as boat and catch confiscation as well as monetary fines. Fishing community members have reported that non-compliance is very low due to these village-level penalties which act as a deterrent through social ostracization (Novak Colwell, 2016).

Other research has shown that the seasonal fishing ban, which halts mechanized fishing for 45 days each year in all coastal states in India, significantly impacts the income of many fishery-dependent stakeholders beyond the harvest sector (Novak Colwell, 2016). For instance, both male and female fish traders lose a statistically significant $(p<0.01)$ amount of overall income during this time. We therefore analyze individuals' responses to the seasonal ban, an expected annual event that poses a stress to many people in coastal communities. The ban may be representative of other stresses, especially stresses incurred as the result of policy decisions that limit resource access. People anticipate the ban each year, just as one may anticipate the rainy season or another policy that places yearly constraints on their livelihoods.

\section{(b) Data collection}

Data collection took place during the 2015 seasonal fishing ban (during weeks 4 and 5 of the ban period, 6-20 May 2015). Tamil Nadu state (TN) and nearby Puducherry Union Territory have extensive marine fish production and value (CMFRI, 2015). Parts of Puducherry, including the study site, are surrounded by Tamil Nadu territory (Figure 1). Nagappattinam district (TN) and Karaikal (Puducherry) were chosen as the study districts because of their historically prominent role in marine fishing in the area. Karaikal district is couched 


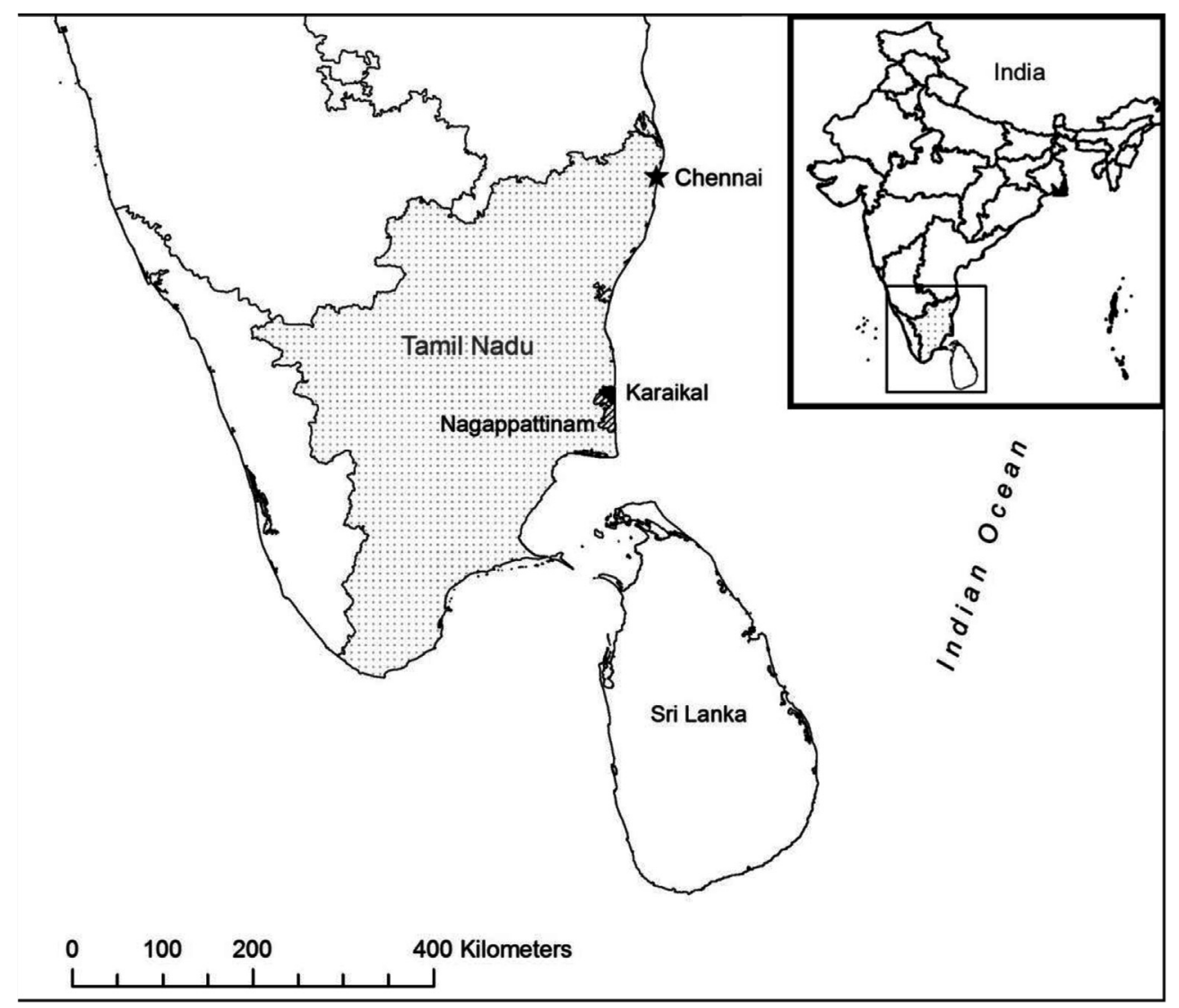

Figure 1. Nagappattinam, Tamil Nadu and Karaikal, Puducherry (map credit: Amanda Tickner, MSU Map Library, 2016).

within Nagappattinam territory, making the physical characteristics of the coastal fishery similar between the two districts. There are 68 villages within Nagappattinam and Karaikal territory that have historically worked together to solve fishery issues. Fishery policies in Karaikal largely follow Nagappattinam decisions due to the historical legacy of fishing in the area and the geographical location of Karaikal (Swamy, 2011).

Two villages were chosen based on 2010 Marine Fisheries Census data for Tamil Nadu (CMFRI, 2010b) and Puducherry territory (CMFRI, 2010a). Villages within these territories were selected based on similarities in demographic profiles (prevalence of below poverty line (BPL) residents, education level, caste, and religion), as well as similarities in boat distribution patterns (i.e., mechanized owners/laborers are in the majority in each village, though motorized boat fishing is also prevalent in both). To determine villages without significant differences in the above categories, we performed ChiSquared tests using the relevant 2010 Marine Fisheries Census data. Additionally, because of the geographical location of these areas, it was also important to select villages that experienced similar impacts from the 2004 Indian Ocean tsunami.

Based on the above criteria, we selected Nambiyar Nagar village in Nagappattinam, Tamil Nadu and Kottucherry Medu village in Karaikal, Puducherry. Each village was heavily impacted by the 2004 tsunami. Both areas experienced heavy loss of human life and extensive destruction of infrastructure and fishing assets. The majority of the original housing structures in each village were destroyed. As a result, each village has a tsunami nagar, a cement block housing colony built nearby to the original (old) area of the village by an NGO (Figure 2). However, in Nambiyar Nagar, this colony was built opposite the main road in Nagappattinam, which is roughly $2.5 \mathrm{~km}$ from the sea; whereas in Kottucherry Medu, the tsunami nagar was also built opposite the main road but within $0.5 \mathrm{~km}$ from the sea.

\section{(c) Sampling methods}

The individual was chosen as the unit of analysis because it was assumed that all resources were not necessarily shared equally within the household (Kevane \& Gray, 1999). Given the distinct gender division of labor within fishing communities and various occupational roles available to different individuals, allowing response at the individual level increased the likelihood of capturing the full effects of the ban on different individuals.

Between Nambiyar Nagar and Kottucherry Medu (based on CMFRI, 2010 census data), there were 1851 total adults over the age of 18 . We employed a random sampling strategy within each village to ensure our sample was representative of these 1851 adults. In summary, each village was mapped, houses assigned numbers, and a random number generator was used to identify participants. We oversampled women fishworkers and individuals in fishing unrelated occupations to ensure adequate coverage of these groups, and made sure to control for factors related to sampling in all models. Further details of the randomization process are available from the author's website [https://www.researchgate.net/profile/ Julia_Novak_Colwell].

We weighted the random sample toward Nambiyar Nagar due to its larger size. Our sample included 282 individuals, of whom 18 were not included in this analysis because they 


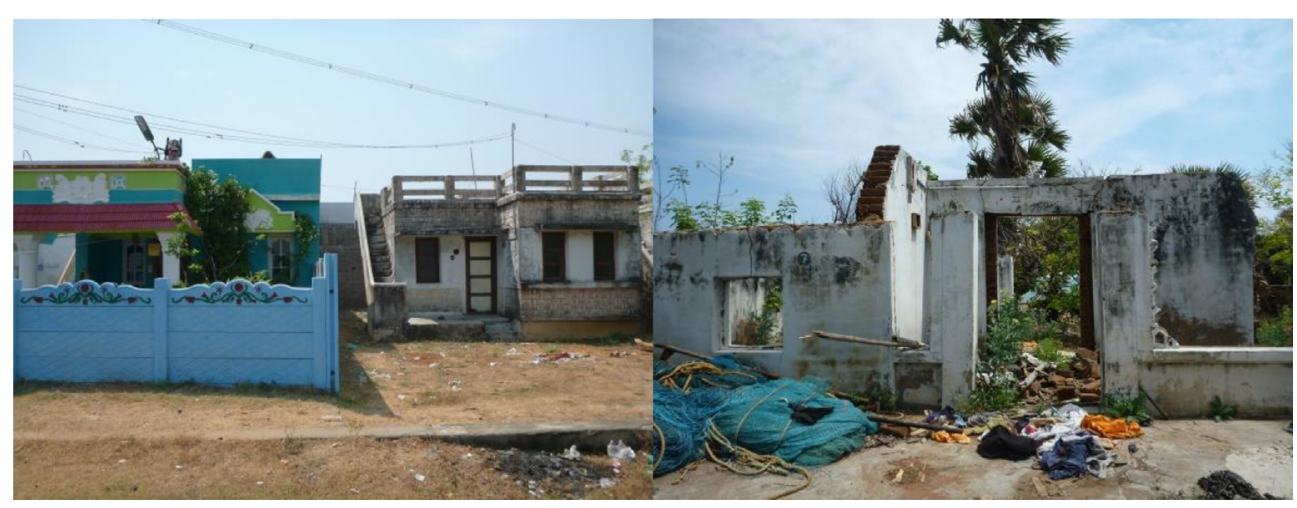

Figure 2. Post-tsunami colony houses on left (some individuals have upgraded their basic tsunami houses as they are able to afford it) and tsunami-destructed house on right [photos by author].

claimed not to experience additional stress during the ban period. The overall response rate in both villages was $75 \%$ (i.e., 127 participants out of 170 total individuals contacted in Kottucherry Medu and 155 of 208 contacted in Nambiyar Nagar). There is no reason to believe the sample is biased as those that declined to participate or dropped out of the survey were spread across sexes.

A structured survey questionnaire was used to gather demographic information, community and group participation, household and productive asset ownership. A seasonal activities calendar was used to solicit information on the stresses an individual faced during this time frame and how they adapted to those stresses (Slocum, 1995). In the seasonal activities calendar, we asked individuals if they were experiencing any stress during the current month. Individuals indicated stresses such as high expenses, lower income, health problems, etc. We then asked participants to indicate how they dealt with those stresses. Individuals were given five options: Took out a loan, asked friends and relatives for help, drew on savings, cut back on food, and/or sold assets. ${ }^{4}$ They were asked to indicate all options they had pursued. Participants were also given the option to fill in any other way they were dealing with their current stresses. This paper analyzes all respondents who indicated dealing with a stress during May 2015 (94\% of the overall sample).

Survey and interview questions, all of which are available on the author's website, were translated into Tamil and delivered face to face (in vernacular Tamil) with the help of two teams of two local research assistants, who the primary author switched off accompanying daily. Additional data were collected through participant observation and interviews with local and state officials. The primary author lived nearby and worked in the fishing community for the period of data collection, interacting with community members, frequenting fish markets and landing sites, attending a village panchayat meeting and local temple festivals.

\section{(d) Qualitative data-informing the quantitative analysis}

Interview data suggest that despite being heavily impacted by the ban in terms of income, post-harvest sector workers, particularly women, were left out of the decision-making and negotiation process when the ban was established for the East Coast, including Tamil Nadu and Puducherry. In the few instances that post-harvest traders were included, those individuals were prominent male fish traders who also owned boats (E. Vivekanandan, personal communication, May 2015). Panchayats, local traditional village governance bodies, play a leading role in rule formation at the village level, as well as an active role in facilitating ban enforcement, within traditional fishing communities. However, over the course of data collection, it was evident that women also have very limited access to this group though they may access it through SHG membership in some cases.

Our interviews suggest that most women, with the exception of SHG members and presidents, consider the panchayat as male-only, reporting they have never been involved in panchayat meetings that discuss proposed village rules. Many stated that only men participate in making the rules. Many indicated that women are not allowed in the meetings unless specifically invited. One woman indicated that one individual from every family is expected to participate, and as long as there is a male of age, that responsibility transfers to him. Therefore, a family member may formally represent a woman at panchayat meetings; however, this formal representation does not guarantee that the representative's interests align with those of female family members, nor does it guarantee distribution of information, either from family to panchayat or the other way around. However, when asked whether they were willing to bring up issues to the panchayat (i.e., issues that affect the whole village, like standing water), most women answered in the affirmative. Therefore, while their actual participation seems minimal, most feel they are able to raise issues and potentially be heard indirectly.

The majority of men, on the other hand, answered that they directly participate in meetings and village rule-making with the panchayat. Non-participating men often had specific reasons why they did not participate. One stated that he used to participate, but a few years ago his boat was damaged at sea and the panchayat would not help him get the insurance amount, so he therefore stopped attending meetings. Another stated that he did not participate because the panchayat is partial toward richer men in the village, so poor and middle-class people do not participate because the rich people do not take their opinions seriously.

When asked about panchayat participation, one boat owner stated that Yes, I participate as they give importance to the boat owners. ${ }^{5}$ A previous panchayatar (member of the village panchayat) indicated, when asked who participates in the meetings, that educated people, important people, people from big families, and the panchayatars are those that participate. This indicates that class also might play a significant part in an individual's relative power, as measured through participation in village decision-making. As such, there is extensive variation in power and class among both men and women. We explore these relationships in the analysis below. 


\section{(e) Quantitative data}

The dependent variable, reactive strategies, is a dichotomous variable that differentiates between those individuals who use only proactive adaptation strategies and those who resorted to reactive strategies as well. The variable is coded as " 0 " (i.e., proactive) for those individuals employing only proactive adaptation strategies: asking friends and relatives for help, drawing on savings, or taking a loan. It is coded as " 1 " (i.e., reactive) for those who resort to selling assets or cutting back on food. This delineation between adaptive and reactive strategies is adapted from Corbett's (1988) work on famine in sub-Saharan Africa, where modifying food intake and selling assets are considered reactive responses to crisis. While in Corbett's analysis, taking a loan is considered reactive coping, we argue that in the context of Tamil Nadu fishing villages, taking a loan is a very common occurrence and not a lastditch strategy. Taking a loan from a financial institution indicates sufficient assets for collateral, while taking a loan from neighbors is a form of social network building. Additionally, many individuals report planning to take loans during the ban period because they can repay the loan post-ban with the help of government ban compensation (usually received in late June or early July). This indicates an adaptation or ex ante risk management strategy. Many individuals do employ multiple strategies. Responses were coded as reactive if they employ any reactive coping, even if they also pursue ex ante adaptations.

Power relationships and class differences between individuals play an important part in producing varied experiences of gender (Jackson, 1993). We therefore operationalize sex, power, and class by looking at the following measurable indicators, as summarized in Table 1 below. ${ }^{6}$ First, sex is operationalized as male vs. female based on respondent selfidentification.

There are a number of different ways to operationalize power in line with Allen's facets of power. The first facet is Power Over, which is operationalized by one variable: Power 1 is Panchayat membership or prior membership, of which there are very few observations $(n=7)$, all of whom are male. We do not expect this measure to play a significant role in explaining an individual's likelihood of turning toward a reactive strategy. However, panchayatars have significant sway over village happenings at every level from the personal (marriage disputes) to higher level inter-village negotiations on fishing rules.

The second facet is Power With as measured by variable Power2: participation in an SHG, political party or panchayat meeting. This is a measure of the power derived from group agency. This measure is relevant because some women report SHG members being involved in panchayat meetings, indicating that in some cases women may use this avenue as a means of access to village decision-making powers (i.e., an individual has a network that enables power to achieve certain goals). Women may also use SHGs to access large group loans, something unachievable as an individual. Men also either indicated that they participate in panchayat meetings or political parties to make the village better and contribute to positive change.

The third facet is Power To which is measured by two variables. The first variable is Power3: report of notifying the panchayat of a village problem. This type of power is derived from an individual's willingness to bring an issue to the attention of village authorities and be confident that their voice will be heard and taken seriously (i.e., the power to act). The second variable is Power4: whether an individual has a network outside of their village or villages within their direct vicinity. The logic behind the $\mathrm{P} 4$ variable is that individuals with contacts in major cities or other countries may have enhanced ability (i.e., power) to adapt by finding alternative work through the network.

There are two measures used as proxies for class, both of which are based on financial capital measurements and one's status in the labor process. Class 1 is a measure of fishing asset ownership, spanning from no assets (value $=0$ ) to those owning multiple boats (value $=4$ ). One drawback of this measure is that it artificially deflates class representation for the small sample of individuals working in fishing-unrelated work, such as auto drivers or shop owners who may have other types of productive assets. ${ }^{9}$ However, we nonetheless include this variable because it may indicate concerns related to overspecialization.

The second measure of class, Class 2, indicates ownership of household assets. High levels of wealth are indicated by ownership of land or an air conditioning unit. Middle wealth is indicated by ownership of at least two of the following three assets: refrigerator, gas stove, and mixy-grinder. Finally, the lowest class is indicated by possession of a government TV. TVs are given by the government but are of poor quality and very small. All individuals who can afford to upgrade to a bigger TV do so. These divisions are based on extensive local consultation regarding the bundle of assets that divide social classes. Class 2 operationalizes class as a manifestation of financial strength (Nightingale, 2011), while fishing asset ownership operationalizes an individual's role within the production sector.

Finally, we controlled for participants' level of formal education because education can affect an individual's income and adaptation opportunities (Ellis, 1998). This variable ranges across five ordered categories, from 0 to 4 (with 0 indicating no formal schooling and 4 indicating college or higher education).

\section{(f) Analysis}

Chi-squared Test of Independence was used to assess whether adaptation strategy (partitioned into the five possible adaptive/coping choices) differed by sex. All other analyses consider only the dichotomous version of the dependent variable. Therefore, logistic regressions were run in Stata with each predictor variable separately to determine main effect significance. These results indicated that, of the predictor variables, only sex and C2-Household assets are significant (at the $p<0.1$ level) in predicting an individual's likelihood of resorting to reactive coping. Due to the large number of combined variable possibilities, Minitab software was utilized to perform stepwise linear regression for variable selection. Stepwise linear regression converges on main effect and interaction effect predictors that best explain the model outcome (i.e., an individual's likelihood of resorting to reactive coping). All predictor variables were included in Minitab for variable selection. Variable selection indicated that the main effects variables sex, P1-Panchayatar, and C2-Household assets explained the outcome of the model best. Additionally, the variable selection process indicated the interactions between C2-Household assets and P4-Network, as well as sex and P3-Notify as interactions that best explain model outcome. After variable selection, STATA was used to model the relationships among selected variables and the outcome variable (reactive coping) using logistic regression. Finally, we partitioned the data by sex, power levels, and class in order to clarify the interactions among these variables (Braumoeller, 2004). By controlling for each of these factors in some models, and 
Table 1. Dependent and independent variable matrix ${ }^{\mathrm{a}}$

\begin{tabular}{|c|c|c|c|c|}
\hline Variable & Type & Male $n$ & Female $n$ & Values \\
\hline Dependent: & Dichotomous & 132 adaptive only & 61 adaptive only & $0=$ adaptive strategy only \\
\hline Reactive coping & & 37 reactive & 34 reactive & $1=$ reactive strategy \\
\hline Independent: & Dichotomous & 169 & 95 & $0=$ Male \\
\hline Power1: Panchayat member & Dichotomous & $7 / 169$ are members & $0 / 84^{\mathrm{b}}$ are members & $\begin{array}{l}0=\text { Not a member } \\
1=\text { Panchayat member }\end{array}$ \\
\hline $\begin{array}{l}\text { Power2: Participation (in SHG, political } \\
\text { party or panchayat meetings) }\end{array}$ & Dichotomous & $141 / 169$ participate & 51/84 participate & $\begin{array}{l}0=\text { No group participation } \\
1=\text { Group participation }\end{array}$ \\
\hline Power4: Outside village network & Dichotomous & 146/169 have networks & $55 / 95$ have networks & $\begin{array}{l}0=\text { No outside local villages network } \\
1=\text { Outside local villages network }\end{array}$ \\
\hline Class1: Asset ownership-Fishing & Ordinal & $\begin{array}{l}0=88 \\
1=1 \\
2=2 \\
3=32 \\
4=5\end{array}$ & $\begin{array}{l}0=58 \\
1=19 \\
2=1 \\
3=15 \\
4=2\end{array}$ & $\begin{array}{l}0 \text { (none) }-4 \text { (multiple boats) } \\
\text { 1. fishing baskets/boxes } \\
\text { 2. fishing nets only } \\
\text { 3. boat } \\
\text { 4. multiple boats }\end{array}$ \\
\hline $\begin{array}{l}\text { Control variable: } \\
\text { Education }\end{array}$ & Ordinal & $\begin{array}{l}0=13 \\
1=72 \\
2=28 \\
3=6\end{array}$ & $\begin{array}{l}0=55 \\
1=30 \\
2=9 \\
3=1\end{array}$ & $\begin{array}{l}0-4 \\
\text { 1. No education } \\
\text { 2. Primary school }(1-5) \\
\text { 3. Secondary school }(6-10) \\
\text { 4. High school } \\
\text { 5. College or above }\end{array}$ \\
\hline
\end{tabular}

${ }^{a}$ A correlation matrix is available in the online appendix on the first author's website.

${ }^{\mathrm{b}}$ Please note that some women were not presented the full survey due to time constraints. Therefore, analyses including these variables have a smaller total number of observations.

holding their values constant in others through partitioning, we eliminate concerns about relationships among the explanatory variables. Primary findings are presented below, and additional results are available from the authors.

\section{RESULTS AND DISCUSSION}

\section{(a) Is there always a sex divide regardless of power and class?}

The literature suggests that there is a relationship between sex and the deployment of reactive coping. Results from the chi-squared test of independence (Table 2) indicate that this relationship holds within our data set as well $\left(X^{2}(4\right.$, $N=264)=27.73, p<0.01)$.

However, the regression results for the likelihood of resorting to a reactive coping strategy as predicted by sex, power, and class measures are presented in Table 3. Women are, in fact, more likely than men to pursue reactive coping strategies (Table 3, model $1, b=0.69, p=0.02$ ) in this sample. However, this effect does not hold when controlling for both main effect variables and interaction effect variables, possibly due to important interactions between sex and these other variables (Table 3, models 3). In other words, the sex divide is driven by other factors that condition the impact of sex differences, such as power and class.

Women are more likely than men, on average, to rely on reactive strategies (Model 1). However, the above results suggest variation within female and male populations as well.
Table 2. Chi-squared test of independence indicating relationship between sex and adaptation/coping strategy utilized.

\begin{tabular}{lcc}
\hline Strategy & Male & Female \\
\hline Savings & 54 & 13 \\
Ask relatives for help & 28 & 7 \\
Took loan & 98 & 72 \\
Pledged jewels & 27 & 24 \\
Cut back on food & 6 & 15 \\
\hline
\end{tabular}

$\mathrm{df}=4, \mathrm{X}^{2}=27.73, p<0.01$.

Therefore, we partitioned the sample in order to determine what factors affect stress responses within each group.

We hypothesized that the sex divide is contingent on levels of power and class, such that the sex divide in reactive coping would be less pervasive at upper class and high power levels. In fact, results suggest that the sex divide is only significant when individuals have no external network (i.e., have low power to act) (Table 4 , model $4, b=1.46, p=0.02$ ). The sex divide is insignificant (model $5, b=0.25, p=0.49$ ) among people who have an external network (i.e., higher power). Similarly, the sex divide is only substantial and significant among lower class levels (model $6, b=0.73, p=0.08$ ), with coefficients and significance declining as assets increase (middle class: model $7, b=0.32, p=0.49$; upper class: model 8 , $b=0.11, p=0.93$ ). Based on this evidence, we can reject the null hypothesis in support of the first alternative hypothesis: there is a sex divide in likelihood of employing a 
Table 3. Logistic regression results for factors impacting an individual's turn toward reactive coping (conducted in Stata)

\begin{tabular}{lccc}
\hline Variable & $\begin{array}{c}(1) \\
\text { Bivariate logistic regression } \\
\text { for overall sex divide }\end{array}$ & $\begin{array}{c}(2) \\
\text { Regression with main } \\
\text { effects variables }\end{array}$ & $\begin{array}{c}(3) \\
\text { Regression with main } \\
\text { effects \& 2-way interactions selected } \\
\text { by step-wise regression }\end{array}$ \\
\hline Sex (female) & $0.69^{* *}(0.28)$ & $0.50^{*}(0.31)$ & $0.41(0.48)$ \\
P1-Panchayatar & & $1.36^{*}(0.81)$ & $1.31(0.82)$ \\
P3-Notify & & & $0.17(0.43)$ \\
P4-Network & & $-0.50^{* *}(0.25)$ & $-0.12(0.98)$ \\
C2-Household Assets & & & $-0.47(0.52)$ \\
C2*P4 & $-1.96^{* * *}(0.43)$ & $-0.43(0.47)$ & $-0.06(0.59)$ \\
Sex P3 & 264 & 253 & $0.24(0.64)$ \\
Constant & 0.02 & 0.03 & $-0.28(0.94)$ \\
N & & 253 & 0.04 \\
Pseudo $\mathrm{R}^{2}$ & & & 0.04 \\
\hline
\end{tabular}

$p<0.1^{*}, p<0.05^{* *}, p<0.01^{* * *}$, standard errors in parentheses.

Table 4. Impact of sex on reactive coping for various configurations of power and class

\begin{tabular}{|c|c|c|c|c|c|}
\hline Variable & $\begin{array}{c}(4) \\
\text { No Network } \\
(\text { Power } 4=0 \text { ) }\end{array}$ & $\begin{array}{c}(5) \\
\text { Network } \\
(\text { Power } 4=1)\end{array}$ & $\begin{array}{c}(6) \\
\text { Lower Class } \\
(\text { Class } 2=1)\end{array}$ & $\begin{array}{c}(7) \\
\text { Middle Class } \\
(\text { Class } 2=2)\end{array}$ & $\begin{array}{c}(8) \\
\text { Upper Class } \\
(\text { Class } 2=3 \text { ) }\end{array}$ \\
\hline Sex & $1.46^{* *}(0.63)$ & $0.25(0.36)$ & $0.73^{*}(0.42)$ & $0.32(0.46)$ & $0.11(1.24)$ \\
\hline Constant & $-1.56(0.55)$ & $-1.23^{* * *}(0.20)$ & $-0.89^{* * *}(0.32)$ & $-1.52^{* * *}(0.27)$ & $-1.20^{* * *}(0.47)$ \\
\hline$N$ & 63 & 201 & 100 & 134 & 30 \\
\hline Pseudo $R^{2}$ & 0.07 & 0.00 & 0.02 & 0.00 & 0.00 \\
\hline
\end{tabular}

reactive strategy, but this result is driven by groups who have low levels of power and/or class.

\section{(b) Do power and class have different impacts for men and women?}

Much like the impacts of sex on adaptation behavior, asset availability also appears initially to impact an individual's likelihood of resorting to reactive coping strategies. Reactive responses are less likely, on average, with increasing levels of household assets (Table 3, model 2, $b=-0.50, p=0.04$ ). These results indicate that additional household assets decrease one's likelihood of resorting to reactive coping. Selling productive household assets has been shown by some scholars to be a primary coping strategy of individuals and families in times of need (Allison \& Seeley, 2004), and this pattern is evident when lower class individuals more commonly resort to reactive strategies such as selling off assets (though in our case it is reflective of selling gold assets instead of productive household assets). However, as with the sex divide, this result loses significance when some additional controls are included in the model (Table 3, model 3). The interactions are also not jointly significant when tested along with their component parts.

To that end, we hypothesized that power and class have different impacts for men and women, and we therefore partitioned the model by sex and/or power capabilities (Tables 5 and 6) in order to determine the conditions under which household assets affect stress responses. The data support this differentiated impact hypothesis.

When all men or all women are considered as uniform groups, household asset ownership does not significantly impact the likelihood of reactive strategies (Table 5, models 9 and 10). However, when these groups are further subdivided by participants' network capabilities (Table 6), the results indi-
Table 5. Impact of power and class on reactive coping for men and women

\begin{tabular}{lcc}
\hline Variable & $(9)$ & $(10)$ \\
& Women & Men \\
\hline P4-Network & $-1.03^{* *}(0.45)$ & $0.36(0.59)$ \\
C2-Household & $-0.17(0.39)$ & $-0.28(0.29)$ \\
Constant & $0.32(0.61)$ & $-1.08(0.74)$ \\
$N$ & 95 & 169 \\
Pseudo $R^{2}$ & 0.05 & 0.00 \\
\hline$p<0.1^{*}, p<0.05^{* *}, p<0.01^{* * *}$, standard errors in parentheses.
\end{tabular}

cate an inverse relationship between class and reactive strategies only among women who have access to a network (model 14, $b=-1.04, p=0.08$ ), but not for other groups. In other words, much of the initial class-based result (Table 3, model 2) is driven by a subset of the female population that has access to external networks. In contrast with other studies (e.g., Allison \& Seeley, 2004) showing that household assets help avoid reactive responses, this result demonstrates that these assets may only mitigate such concerns under narrow conditions.

The impact of power is dependent on the aspect of power being assessed. Although the sample of panchayatars is small $(n=7)$ and completely male dominated, when controlling for class effects, being a panchayatar (P1) actually increases the likelihood of reactive coping (Table 3 , model $2, b=1.36$, $p=0.10$ ), and this result remains robust even with the addition of other control variables. This appears to be an unexpected result, given that panchayatars generally are of higher power (due to their position) within the village and therefore not expected to resort to suboptimal reactive coping. In examining the data, individuals in this group who resorted to reactive coping do so solely by selling assets (i.e., pledging gold to the bank) and not cutting back on food. Two of the 
Table 6. Impact of C2-Household assets on reactive coping for non-networked and networked women and men

\begin{tabular}{lcccc}
\hline Variable & $(11)$ & $(12)$ & $(13)$ & $(14)$ \\
& Women without a network & Men without a network & Men with network & Women with network \\
\hline C2-Household & $-0.38(0.58)$ & $0.05(1.04)$ & $-0.31(0.30)$ & $-1.04^{*}(0.59)$ \\
Constant & $0.40(0.82)$ & $-1.64(1.90)$ & $-0.67(0.59)$ & $0.62(0.93)$ \\
$N$ & 40 & 23 & 146 & 55 \\
Pseudo $R^{2}$ & 0.01 & 0.00 & 0.01 & 0.05 \\
\hline
\end{tabular}

$p<0.1^{*}, p<0.05^{* *}, p<0.01^{* * *}$, standard errors in parentheses.

Table 7. Impact of P4-Network on reactive coping for women and men of low and medlupper class

\begin{tabular}{lcccc}
\hline Variable & $(15)$ & $(16)$ & $(17)$ & $(18)$ \\
& Low-class women & Med-upper class women & Low-class men & Med-upper class men \\
\hline P4-Network & $-0.19(0.56)$ & $-1.69^{* *}(0.81)$ & $1.02(1.31)$ & $-0.08(0.70)$ \\
Constant & $-0.07(0.37)$ & $-0.18(0.61)$ & $41.79^{*}(1.08)$ & $-1.47^{* *}(0.64)$ \\
$N$ & 52 & 0.10 & 48 & 96 \\
Pseudo $R^{2}$ & 0.00 & 0.02 & 0.00 \\
\hline
\end{tabular}

$p<0.1^{*}, p<0.05^{* *}, p<0.01^{* * *}$, standard errors in parentheses.

three individuals in this group who resorted to reactive coping own one or multiple boats, making ban time maintenance costs quite high. This may suggest that being in an upper class category and owning inflexible assets necessitates high spending: if an individual cannot meet their expenses, it forces them to react. This finding supports current scholarship indicating that overspecialization in a particular industry can limit adaptive options (Allison \& Ellis, 2001).

This panchayat finding, though limited by sample size, also raises questions about interpreting the adaptation choices of those who have higher power or assets. The implications of upper class/higher power individuals pledging gold may be vastly different than those individuals of lower class/power doing the same. Within the fishing village, pledging gold and taking a loan are considered two different responses to financial stress. Two common scenarios illustrate the typical difference between taking loans and pledging gold: 1) an individual pledges gold (i.e., sells it to the bank ${ }^{10}$ ) knowing they eventually will be able to buy it back with interest, OR 2) an individual pledges gold to the bank (i.e., sells it to the bank) knowing that they will not be able to buy it back (with the compounded interest). In other words, the first scenario has implications for future opportunities (because of paid interest). However, these implications are minimal in comparison with the second scenario, which results in decreased assets available for future crisis response. Given the earning potential of mechanized boat owners, the first scenario appears more likely for the panchayatars. Upper class/higher power individuals may use gold as collateral in times of short-term need, under the assumption that later profits will allow them to recoup their gold for the next time, similar to other loan arrangements. Nonetheless, the interest to recover pledged gold still reduces these individuals' available capital for future efforts. This finding highlights the importance for future analysis of disaggregating adaptation and coping responses into more detailed categories to understand more nuanced patterns in individuals' options. Further exploration of the meaning and use of gold by different segments of the population is also warranted.

External networks (P4) also appear to affect coping strategies, but only in particular situations. For women, being connected to an external network significantly decreases their likelihood of resorting to reactive coping strategies (Table 5, model $9, b=-1.03, p=0.02$ ). In contrast, connection to an external network does not significantly impact men's likeli- hood of reacting. This result indicates that the outside village network plays a greater role for women than men in enabling them to draw on extra resources during times of hardship. These extra resources may give them the power to adapt and successfully employ ex ante risk management strategies rather than ex post coping reactions. Partitioning by class level (Table 7), we demonstrate that this effect is driven by one particular group: only middle-to-upper class women significantly benefit from networks (model 16, $b=-1.69, p=0.04$ ) while their lower class counterparts do not (model 15, $b=-0.19$, $p=0.73$ ).

These findings suggest that the reported importance of networks to women in particular, as indicated in other studies (Berry, 1989; Ray, 2007; Young, 1993), may not always translate into benefits to all women, only those of certain class groups. This finding further suggests that women in the study villages may require both networks and some basic level of household assets in order to avoid reactive responses. Men, in contrast, may have other ways to avoid damaging their future prospects. Further research is therefore necessary to unpack the reported benefits of networks to women. Where this relationship is consistent with our findings, development initiatives that focus on network building for women may also benefit from incorporating a dual aim of increasing women's access to capital (financial or otherwise) to ensure benefits reach the most vulnerable.

Overall, these results suggest that women, unlike men, require some additional support-networked power and/or household assets - in order to avoid reactive responses to seasonal livelihood stress in the study villages. In line with Arora-Jonsson's (2011) warning, this outcome also highlights disparities among women, demonstrating the need for decision makers to consider more nuanced gender differences rather than the simplistic sex divide.

\section{CONCLUSION}

In the beginning of this paper, we asserted that looking at NRM issues through a lens of intersectionality provides valuable insight into people's livelihood choices that traditional models of gender and the environment do not. By examining gender as intersecting arrangements of sex, power, and class, we demonstrated that sex by itself may not explain differences 
in livelihood adaptation and coping choices. Instead, women and men both may exhibit within-group variation in terms of livelihood stress responses. The relationships previously identified by scholars regarding gender and the environment, and the sex divide in reactive coping, are not driven by sex alone in the study villages, but rather by configurations of power and class within each sex.

In particular, this research supports others' conclusions about the importance of networks and household assets, particularly for women, in adapting to livelihood stresses. However, this research also suggests that networks may not have the same significance to all women. A minimum threshold of assets appears necessary in order for women to benefit from their access to networks when coping with harvest restraints in this region. When examining the importance of networks to individuals, an enhanced understanding of their utility may require assessing the context-specific impact of not only an individual's sex but also of their class.

In this study, by incorporating these components and demonstrating how they interact with each other, we showed characteristics of individuals that are more and less likely to fall back on reactive coping strategies. The findings suggest the utility of initiatives that help individuals build tools necessary to ensure sustainable livelihoods. For decision makers aiming to increase livelihood resilience, it may be worthwhile to consider strategies that build certain high-risk groups' networks, at least in areas where such relationships are shown to decrease women's reliance on strategies that have negative livelihood implications. However, this strategy may not work in contexts where community members may need additional assets first in order to benefit from networks. It is essential to consider applicability to local conditions, for example the impacts on less homogenous communities that employ networks in different ways.

Additionally, the study villages were heavily impacted by the 2004 Indian Ocean Tsunami, another contextual factor that may affect social network formation and impacts. This event had a huge impact on social networks and community cohesiveness: large segments of the surviving population in each village moved to newly constructed housing colonies of varying distances from the old areas of each village. Research on displaced individuals in other contexts has suggested that the displacement faced by individuals after a major disaster severs social networks, greatly impacting an individual's ability to adapt or cope with livelihood fluctuations (Berry, 1989). Additionally, the aid that arrived post-tsunami was so extensive that it was termed "the second tsunami" (Kruks-Wisner, 2011). For these reasons, it is probable that indicators of power and class within tsunami affected areas are different than in other areas, particularly due to the widespread distribution of aid in this context.

For this reason, when conducting NRM research that incorporates intersectionality, it is important to assess locally relevant measures of power and class. Blanket measurements that are not contextualized, such as household asset ownership, may have different impacts in other settings. Nonetheless, our results demonstrate one set of relationships in which sex alone does not completely guide adaptation differences without considering its intersectionality with other factors.

\section{NOTES}

1. Caste may correlate with class but in a very different way from the Marxian purely economic class.

2. West Coast states implement the seasonal ban beginning 15 June instead.

3. However, since it is not possible to know an individual's class or power levels prior to surveying them, we cannot completely rule out the possibility of selection bias based on these factors.

4. In all cases, those individuals who chose "sold assets" indicated that they sold or pledged (as collateral to a bank) their gold.

\section{Translations by bilingual research assistants and first author.}

6. Caste has been argued to be an important conditioning factor of sex as well (Nightingale, 2011). As caste does not vary in our sample (our entire sample was from the same caste: Pattinavar), we are able to focus on other factors such as class and power.
7. Although there is a significant literature on how to define gender, and in particular, sex, our entire sample self-identified as either male or female.

8. We acknowledge the possibility there may be omitted variable bias concerning the way in which an individual obtains these measures of power. However, we control for important potential drivers of power and adaptive capacity (i.e., wealth and education) in the analysis.

9. It artificially deflates this class measure for fish traders as well. However, it has a smaller impact on this group because most fish traders own at least fishing baskets (captured in Class1: Level 1 variable), even though they do not harvest fish for a living.

10. A brief account of gold bank loans is included in Sinha's (2005) account of informal credit sources and microfinance in India (Sinha, 2005).

\section{REFERENCES}

Agarwal, B. (2001). Participatory exclusions, community forestry, and gender: An Analysis for South Asia and a Conceptual Framework. World Development, 29(10), 1623-1648. http://dx.doi.org/10.1016/ S0305-750X(01)00066-3.

Allen, A. (1998). Rethinking power. Hypatia, 13(1), 21-40.

Allison, E. H., \& Ellis, F. (2001). The livelihoods approach and management of small-scale fisheries. Marine Policy, 25, 377-388.
Allison, E. H., \& Seeley, J. a. (2004). HIV and AIDS among fisherfolk: A threat to "responsible fisheries"?. Fish and Fisheries, 5(3), 215-234. http://dx.doi.org/10.1111/j.1467-2679.2004.00153.x.

Arora-Jonsson, S. (2011). Virtue and vulnerability: Discourses on women, gender and climate change. Global Environmental Change, 21(2), 744-751. http://dx.doi.org/10.1016/j.gloenvcha. 2011.01.005. 
Barrig, M. (2006). What is justice? Indigenous women in Andean development projects. Women and Gender Equity in Development Theory and Practice, 107-133.

Béné, C., Belal, E., Baba, M. O., Ovie, S., Raji, A., Malasha, I., .. Neiland, A. (2009). Power struggle, dispute and alliance over local resources: analyzing "democratic" decentralization of natural resources through the lenses of Africa Inland fisheries. World Development, $\quad 37(12), \quad$ 1935-1950. http://dx.doi.org/10.1016/ j.worlddev.2009.05.003.

Bennett, E. (2005). Gender, fisheries and development. Marine Policy, 29 (5), 451-459. http://dx.doi.org/10.1016/j.marpol.2004.07.003.

Berry, S. (1989). Social institutions and access to resources. Africa, 59(1), 41-55.

Braumoeller, B. F. (2004). Hypothesis testing and multiplicative interaction terms. International Organization, 58(4), 807-820. http://dx.doi. org/10.1017/S0020818304040251.

Braun, Y. A. (2015). Interrogating large-scale development and inequality in Losotho: Bridging feminist political ecology, intersectionality, and environmental justice frameworks. In S. Buechler, \& A.-M. S. Hanson (Eds.), A political ecology of women, water and global environmental change (pp. 19-37). New York: Routledge.

Buvinić, M., \& Gupta, G. R. (1997). Female-headed households and female-maintained families: Are they worth targeting to reduce poverty in developing countries?. Economic Development and Cultural Change, 45(2), 259-280.

Carney, J. (1994). Contracting a food staple in the Gambia. In P. Little, \& M. Watts (Eds.), Living under contract: Contract farming and agrarian transformation in sub-Saharan Africa (pp. 161-187). Madison, WI: University of Wisconsin Press.

CMFRI (2010a). Marine Fisheries Census 2010 - Puducherry. Kochi.

CMFRI (2010b). Marine Fisheries Census 2010 - Tamil Nadu. Kochi.

CMFRI (2015). 2014-2015 Annual Report. Kochi.

Corbett, J. (1988). Famine and household coping strategies. World Development, 16(9), 1099-1112. http://dx.doi.org/10.1016/0305-750X (88)90112-X

Cornwall, A. (2003). Whose voices? Whose choices? Reflections on gender and participatory development. World Development, 31(8), 1325-1342. http://dx.doi.org/10.1016/S0305-750X(03)00086-X.

Davis, K. (2008). Intersectionality as buzzword: A sociology of science perspective on what makes a feminist theory successful. Feminist Theory, 9, 67-85.

de Haan, L., \& Zoomers, A. (2005). Exploring the frontier of livelihoods research. Development and Change, 36(1), 27-47. http://dx.doi.org/ 10.1111/j.0012-155X.2005.00401.x.

Detraz, N. (2017). Gender and the environment. Cambridge, United Kingdom: Polity Press.

Ellis, F. (1998). Household strategies and rural livelihood diversification. Journal of Development Studies, 35(1), 1-38. http://dx.doi.org/10.1080/ 00220389808422553.

Ellis, F. (2000). Rural livelihoods in developing countries. Oxford: Oxford University Press.

Hapke, H., \& Ayyankeril, D. (2004). Gender, the work-life course, and livelihood strategies in a South Indian fish market. Gender, Place and Culture: A Journal of Feminist Geography, 11(908303972), 229-256. http://dx.doi.org/10.1080/0966369042000218473.

Haque, C. E., Idrobo, C. J., Berkes, F., \& Giesbrecht, D. (2015). Smallscale fishers' adaptations to change: The role of formal and informal credit in Paraty, Brazil. Marine Policy, 51, 401-407. http://dx.doi.org/ 10.1016/j.marpol.2014.10.002.

Hawkins, R., \& Ojeda, D. (2011). Gender and environment: critical tradition and new challenges. Environment and Planning D: Society and Space, 29(2), 237-253. http://dx.doi.org/10.1068/d16810.

Heltberg, R., Hossain, N., Reva, A., \& Turk, C. (2012). Anatomy of Coping - Evidence from People Living through the Crises of 2008-11 (No. 5957). Policy Research Working Paper.

Hussein, K., \& Nelson, J. (1998). Sustainable Livelihoods and Livelihood Diversification. IDS Working Paper, 69, 32, Retrieved from http://opcprd.ubib.eur.nl:8080/DB=3/LNG =EN/PPN?PPN=236411659/.

ICSF (2005). Post-tsunami rehabilitation of fisheries livelihoods: ICSF information dossier. Chennai.

Jackson, C. (1993). Doing what comes naturally? Women and environment in development. World Development, 21(12), 1947-1963. http:// dx.doi.org/10.1016/0305-750X(93)90068-K.

Kabeer, N. (2015). Gender, poverty, and inequality: a brief history of feminist contributions in the field of international development. Gender
\& Development, 23(2), 189-205. http://dx.doi.org/10.1080/ 13552074.2015.1062300.

Kaijser, A., \& Kronsell, A. (2013). Climate change through the lens of intersectionality. Environmental Politics, 23(3), 417-433. http://dx.doi. org/10.1080/09644016.2013.835203.

Kevane, M., \& Gray, L. C. (1999). A woman's field is made at night: Gendered land rights and norms in Burkina Faso. Feminist Economics, 5(3), 1-26. http://dx.doi.org/10.1080/135457099337789.

Kiewisch, E. (2015). Looking within the household: a study on gender, food security, and resilience in cocoa-growing communities. Gender \& Development, 23(3), 497-513. http://dx.doi.org/10.1080/ 13552074.2015.1095550.

Kollmair, M., \& St. Gamper, J. (2002). Sustainable livelihoods approach Switzerland: Aeschiried.

Kruks-Wisner, G. (2011). Seeking the local state: Gender, caste, and the pursuit of public services in post-tsunami India. World Development, 39(7), 1143-1154. http://dx.doi.org/10.1016/j.worlddev.2010.11.001.

Lau, J. D., \& Scales, I. R. (2016). Identity, subjectivity and natural resource use: How ethnicity, gender and class intersect to influence mangrove oyster harvesting in The Gambia. Geoforum, 69, 136-146. http://dx.doi.org/10.1016/j.geoforum.2016.01.002.

McCall, L. (2001). Complex inequality. New York: Routledge.

Niehof, A. (2004). The significance of diversification for rural livelihood systems. Food Policy, 29(4 SPEC. ISS.), 321-338. http://dx.doi.org/ 10.1016/j.foodpol.2004.07.009.

Nightingale, A. J. (2011). Bounding difference: Intersectionality and the material production of gender, caste, class and environment in Nepal. Geoforum, 42(2), 153-162. http://dx.doi.org/10.1016/j.geoforum.2010.03.004.

Njaya, F., Donda, S., \& Béné, C. (2012). Analysis of power in fisheries comanagement: Experiences from Malawi. Society \& Natural Resources, 25(7), 652-666. http://dx.doi.org/10.1080/08941920.2011.627912.

Novak Colwell, J. (2016). Fishery-dependent stakeholders - Impacts and responses to an annual closed fishing season in Tamil Nadu \& Puducherry. India: Michigan State University.

Putnam, R. D. (1993). The prosperous community: Social capital and public life. American Prospect, 3(13).

Ram, K. (1991). Mukkuvar Women: Gender, Hegemony and Capitalist Transformation in a South Indian Fishing Community. North Sydney, Australia: Allen \& Unwin.

Ray, I. (2007). Women, water, and development. Annual Review of Environment and Resources, 32(1), 421-449. http://dx.doi.org/10.1146/ annurev.energy.32.041806.143704.

Rocheleau, D., Thomas-Slayter, B., \& Wangari, E. (1996). Gender and environment: A femiminist political ecology perspective. In D. Rocheleau, B. Thomas-Slayter, \& E. Wangari (Eds.), Feminist political ecology: Global issues and local experiences (pp. 3-26). New York: Routledge.

Rubinoff, J. A. (1999). Fishing for status: Impact of development on Goa's fishermwomen. Women's Studies International Forum, 22(6), 631-644.

Runyan Sisson, A., \& Spike, V. (2013). Dilemmas in world politics: Global gender issues in the new millennium (4th ed.) Boulder: Westview Press.

Self-Help Groups: India (2005). New Delhi.

Shiva, V. (1988). Staying alive: Women, ecology and development. Zed Books, Retrieved from http://books.google.com/books?hl=en\&lr=\& $\mathrm{id}=\mathrm{GPaA} 4 \mathrm{Nb} 0 \mathrm{w} 0 \mathrm{YC} \&$ pgis $=1$.

Sinha, F. (2005). Access, use and contribution of microfinance in India: Findings from a national study. Economic and Political Weekly, 40, 1714-1719.

Slocum, R. (1995). Seasonal activities calendar. In R. Slocum, L. Wichart, D. Rocheleau, \& B. Thomos-Slayter (Eds.), Power and Participation: Tools for change (pp. 181-185). London: Intermediate Technology Publications.

Swamy, R. H. (2011). Disaster capitalism: Tsunami reconstruction and neoliberalism in Nagappattinam, South India Dissertation. The University of Texas at Austin.

Thorpe, A., Pouw, N., Baio, A., Sandi, R., Ndomahina, E. T., \& Lebbie, T. (2014). "Fishing Na Everybody Business": Women's work and gender relations in Sierra Leone's fisheries. Feminist Economics, 20(3), 53-77. http://dx.doi.org/10.1080/13545701.2014.895403.

Toulmin, C. (1992). Cattle, women and well: Managing household survival in the Sahel. Oxford: Clarendon Press.

Vivekanandan, E., Narayanakumar, R., Najmudeen, T. M., Jayasankar, J., \& Ramachandran, C. (2010). Seasonal Fishing Ban (Marine Fisheries Policy Brief No. 2). Kochi. 
Weber, L. (2010). Understanding race, class, gender, and sexuality (2nd ed.) New York: Oxford University Press.

Young, K. (1993). Planning development with women: Making a world of difference. New York: Macmillan Press Ltd., Retrieved from http://www.cabdirect.org/abstracts/19931859001.html;jsessionid=50 BF486F9EE40B4C85E3FD7790FFCBDD.
APPENDIX A. SUPPLEMENTARY DATA

Supplementary data associated with this article can be found, in the online version, at http://dx.doi.org/10.1016/ j.worlddev.2017.04.033.

Available online at www.sciencedirect.com

\section{ScienceDirect}

